\title{
O caráter terapêutico da escrita: Práticas de letramento em um hospital psiquiátrico
}

\author{
Leda Verdiani Tfouni \\ Anderson de Carvalho Pereira \\ Filomena Elaine de Paiva Assolini \\ Milena Sarti \\ Alessandra Adorni \\ Universidade de São Paulo, Ribeirão Preto-SP, Brasil
}

\begin{abstract}
Resumo: Procurou-se investigar práticas de escrita em um trabalho de alfabetização em um hospital psiquiátrico, através do método de análise do discurso. Levou-se em conta o caráter terapêutico da escrita e também a situação de asilamento psiquiátrico. Relata-se o trabalho com letramento desenvolvido durante três meses junto aos internos do hospital. Durante o trabalho, foram privilegiados os eventos que mostravam o envolvimento entre escrita e subjetividade. Através das possibilidades de reconstrução das histórias desses moradores, pode-se contribuir para resgatar lugares da memória apagados pela patologia, e proporcionar, na materialidade discursiva, a reconstrução de suas verdades.
\end{abstract}

Palavras-chave: Alfabetização. Letramento. Sujeito. Escrita.

\section{The therapeutic effect of writing: Literacy practices in a mental health hospital}

Abstract: We investigated literacy practices in a study carried out in a mental health hospital. Both the therapeutic character of writing and the psychiatric institutionalization were considered. The double interdiction to writing was also taken into account, namely: the marginal position towards its singular uses, as well as the stigmatization of those who live under the sign of insanity. During the study, were privileged those events that showed an especial involvement between writing and subjectivity. Thus, through the reconstruction of inmate stories, we could contribute to the recovery of memories effaced by the pathology, and give them the possibility to reconstruct their truth, within the discourse materiality.

Keywords: Literacy. Writing. Subject.

\section{El carácter terapéutico de la escrita: Práctica de la escrita en un hospital psiquiátrico}

Resumen: Se buscó investigar prácticas de escrita en un trabajo de alfabetización en un hospital psiquiátrico, a través del método de análisis del discurso. Se ha considerado el carácter terapéutico de la escrita, y también la situación de asilamiento psiquiátrico. Se relata el trabajo con "escrita" (el proceso socio histórico de adquisición de la escrita) desarrollado durante tres meses junto a los internos del hospital. Durante el trabajo, fueron privilegiados los eventos que mostraban el envolvimiento entre escrita y subjetividad. A través de las posibilidades de reconstrucción de las historias de esas personas, se puede contribuir para rescatar lugares de la memoria borrados por la patología, y proporcionar, en la materialidad discursiva, la reconstrucción de sus verdades.

Palabras clave: Alfabetización. Letramiento. Sujeto. Escritura. 


\section{Introdução}

Foi quase custoso.

A frase, dita por um morador do hospital, exprime em poucas palavras o desafio encarado por todos os envolvidos neste trabalho. Mas do que trata este desafio aqui compartilhado? Este artigo relata o processo e alguns resultados obtidos durante um trabalho de alfabetização de adultos num hospital psiquiátrico de Ribeirão Preto-SP ${ }^{1}$, a partir do conceito de letramento.

Melhor dizendo, tem-se aqui o relato de um trabalho de alfabetização de adultos realizado com participantes cujas capacidades motoras e cognitivas estão comprometidas, devido ao quadro de doença mental e à medicação, com um diferencial, que é a consideração da história de institucionalização de cada participante, marcada pelo isolamento e, com isso, pela perda de contato com as práticas sociais da escrita.

Partindo desse duplo eixo, a proposta do trabalho era, tendo como base a perspectiva discursiva de letramento, possibilitar que ocupassem lugares discursivos novos, ou já apagados da memória, através da introdução de práticas de escrita em seu cotidiano. Tratou-se de um uso motor, cognitivo e, principalmente subjetivo do suporte gráfico da palavra, entendida enquanto substrato simbólico a ser decifrado por todos os participantes, através do uso de portadores de texto que fizessem sentido dentro do pano de fundo de suas experiências subjetivas, como por exemplo, bilhetes, crachás, etc.

Ora, sabe-se que os usos sociais e históricos da escrita são marcados por maneiras conflituosas, ligadas a interesses diversos, ao mesmo tempo em que singularizados por diversos grupos. Dentro dessa consideração, que já sobe à proa do conceito de letramento, que aqui serviu como suporte para indagações e práticas, considerou-se que o asilamento de uma população num hospital psiquiátrico emerge como um dos efeitos dessa complexa rede social tramada pelos usos da escrita, sobretudo enquanto mecanismo jurídico. Como afirma Tfouni (1992b, 2005, 2006) as práticas escritas não estão homogeneamente distribuídas na sociedade. Existem formações discursivas que dependem, para ma- terializar-se lingüisticamente, do uso da escrita, e elas não estão ao alcance de todos, nem de qualquer um, pois dependem de intrincada rede de relações de poder. Deste modo, muitos são excluídos das práticas letradas, mesmo sabendo ler e escrever, porque não compartilham o conhecimento necessário para acessar o modo de funcionamento dessas práticas, enquanto outros o são devido a condições adversas, sócio-econômicas, educacionais, ou psíquicas, como é o caso analisado aqui.

Encarar a possibilidade de trabalhar com essa população foi remexer os percalços ideológicos que afetam todos, quando se admite a possibilidade de trabalhar com uma clientela já tão estigmatizada pelo aparato social. Assim, o propósito maior deste artigo, que traz ecos de um trabalho anteriormente realizado em uma instituição similar (Tfouni \& Seidinger, 1997), foi mostrar como é possível desenvolver um trabalho que tem como suporte a consideração de que a escrita, ao mesmo tempo que tão arraigada numa rede social complexa - em que populações asiladas são colocadas às margens no que se refere às possibilidades de seus diversos usos - também é um recurso para que se resgatem as particularidades do sujeito que escreve, esteja ele em posição de prestígio ou não.

Dentro desse propósito mais amplo, o trabalho aqui relatado contribuiu para o resgate de aspectos da subjetividade dos moradores através dos diversos usos cotidianos da escrita. Para não perder de vista esse objetivo, foi necessário considerar a demanda do grupo que iria ser atendido, bem como o suporte teórico que guiava o trabalho.

A demanda por um trabalho que articulasse práticas de leitura e escrita no contexto de um hospital psiquiátrico levou em conta o caráter terapêutico que a escrita tem quando circula em meio às diversas práticas sociais. Por conta dessa consideração, optouse por trabalhar com as diversas maneiras de introduzir ou resgatar o uso do código escrito, do ponto de vista discursivo (e não normativo), tendo em vista, não o nível de escolarização ou o tempo de

\footnotetext{
${ }^{1}$ Hospital Psiquiátrico de Ribeirão Preto
} 
escolaridade dos moradores, mas atentando-se para os aspectos subjetivos, remetendo-os à história de vida e à memória discursiva de cada um.

No decorrer das atividades propostas, as maneiras pelas quais os moradores se apropriavam dessas práticas foram valorizadas, particularmente as apropriações singulares que faziam do código escrito, o que reforçou aquilo que teoricamente já era considerado enquanto entendimento teórico sobre a escrita: seu papel de estruturadora do convívio social e, assim, como um recurso terapêutico a partir de onde se poderia abrir espaço para que os moradores participantes das atividades propostas pudessem escrever parte de sua própria história. O ponto de partida para essa prática foi o conceito de letramento, que será apresentado a seguir.

\section{$O$ conceito de letramento}

O processo de letramento vem sendo pesquisado desde os anos de 1980, e a ampla circulação dessas investigações atravessa a literatura científica sobre o tema. Para este trabalho, foi fundamental o conceito de letramento proposto por Tfouni (1992a, 1992b, 2001, 2005, 2006). A autora, que é filiada à Análise do Discurso de "linha" francesa, AD, desenvolve há mais de vinte anos pesquisas sobre o tema, tendo procurado em seus estudos separar e distinguir letramento de alfabetização.

Tfouni aborda o letramento como “(...) um processo de aquisição de um sistema escrito por uma sociedade" (1992b, p. 7). Ou seja, é o processo de estar exposto aos usos sociais da escrita que, cumpre ressaltar, não se restringem às práticas de leitura e escrita stricto senso, pois este processo, cuja natureza é sócio-histórica, afeta tanto alfabetizados quanto não-alfabetizados, sujeitos com baixa ou alta escolaridade. Nesse sentido, para ser investigado, o letramento precisa ser remetido às transformações que ocorrem em uma sociedade quando suas atividades passam a ser permeadas por um sistema de escrita cujo uso é generalizado.

Como decorrência disto, pode-se afirmar que em uma sociedade letrada as práticas sociais encontram-se inevitavelmente baseadas no letramento, sendo que a escrita passa a funcionar como mediadora entre estas e o sujeito. Dessa forma, podese então, falar em práticas sociais letradas, que estão mergulhadas em atividades discursivas, denominadas por Kleiman (1995) de eventos de letramento.

Essa visão, portanto, contrapõe-se radicalmente às concepções teóricas que tomam o letramento como sinônimo de alfabetização e/ou postulam uma separação radical entre os usos orais e os usos escritos da língua. Estas teorias que são denominadas de a-históricas por Tfouni (2006), entendem que o uso escrito da língua seria superior ao uso oral, sendo que a primeira modalidade (uso escrito) pode ser definida por um raciocínio abstrato, descontextualizado e lógico e a última (uso oral) tem uma definição que se relaciona a um raciocínio emocional, contextualizado e ambíguo. Alguns autores, cujas formulações são conhecidas como "teorias da grande divisa”, preconizam a separação radical entre esses dois tipos e, muitas vezes, utilizam-se de termos como "pré-lógicos" e/ou "primitivos" para se referir às pessoas que não fazem uso escrito da língua, havendo aí uma idéia de inferioridade, de déficit e de um uso ideal a ser alcançado por todos os usuários de uma língua. Dentres estes autores, destacam-se Heath (1986) e Olson (1986).

Oposta a essa visão, a proposta de letramento trazida por Tfouni (2001) procura mostrar que essa separação entre uso oral e língua escrita é produto de um efeito ideológico, pois de acordo com a autora, existem tanto "características orais no discurso escrito quanto traços de escrita no discurso oral" (Tfouni, 2001, p. 42).

Essa interpretação das duas modalidades seria constituinte de uma sociedade considerada letrada, pois atingiria todos os sujeitos, alfabetizados ou não, com maior ou menor grau de escolaridade e de alfabetização.

Sendo assim, investigar práticas discursivas de uma sociedade, ou de um grupo de sujeitos, implica incorporar a desigualdade e aceitar que essas práticas não estão à disposição de todas as pessoas igualmente, ou seja, o acesso que essas pessoas com 
maior grau de letramento têm a algumas delas é bastante diferente daquelas com baixo grau ${ }^{2}$.

Os sujeitos, portanto, relacionam-se diferentemente com a escrita e, de acordo com o seu grau de letramento poderão ou não construir arquivos, no sentido dado por Pêcheux (1997) e acessar os socialmente disponíveis.

Assim como Tfouni (1994), considera-se aqui que as práticas sociais letradas “(...) influenciam todos os indivíduos de uma sociedade, é claro que de maneira desigual" (Tfouni, 1994, p. 1). Sendo assim, existe um conhecimento sobre a escrita que as pessoas dominam mesmo sem saber ler e escrever, que é adquirido desde que estejam inseridas em uma sociedade letrada. Conseqüentemente, pessoas que vivem em sociedades letradas não podem ser chamadas em hipótese alguma de iletradas, mesmo que não dominem o sistema de escrita desta sociedade e, em decorrência, sejam não-alfabetizadas. Isso ocorre, porque, para pessoas que vivem em uma sociedade letrada, "a exposição às práticas sociais embasadas direta ou indiretamente no uso da escrita é inevitável" (Tfouni, 1994, p. 1).

É preciso ainda destacar que a abordagem sócio-histórica de letramento, tal como é proposta por Tfouni $(2001,2006)$ incorpora um “continuum”, o que possibilita falar em graus de letramento e reconhecer que existem características lingüístico-discursivas que, embora apontadas como exclusivas da escrita, podem estar presentes no discurso oral de analfabetos, ou de sujeitos com baixo grau de letramento, ou pouca ou nenhuma escolaridade. Ao se constatar isso, reconhece-se ao mesmo tempo a interpenetração dos discursos orais e escritos, e a existência de discursos diversos que, por serem produtos sócio-históricos, instalam lugares discursivos diferentes e determinam também relações diferentes entre sujeito e sentido.

Outro ponto importante a ser salientado é que no processo de letramento encaixa-se o de alfabetização.

Nessa perspectiva, Tfouni $(2001,2006)$ esclarece que existem letramentos de natureza variada, inclusive sem a presença de alfabetização.

A filiação de Tfouni à Análise do Discurso de "linha" francesa permitiu-lhe refinar os conceitos de autoria propostos por Foucault (1969) e Orlandi e Guimarães (1988).
Tfouni $(2001,2006)$ considera o autor como uma posição discursiva, diferente da de escritor e de narrador (Maingueneau, 1989). O autor é uma posição de sujeito a partir da qual ele consegue estruturar seu discurso (oral ou escrito) de acordo com um princípio organizador contraditório, porém necessário, visto que existe, no processo de produção de um texto um movimento de deriva e dispersão de sentidos inevitável, que o autor precisa “controlar" (Tfouni, 2001, 2005), a fim de dar ao seu discurso uma unidade aparente com começo, meio e "fechamento" (termo de Gallo, 1995).

Para Tfouni (2005, 2006), o trabalho de autoria situa-se naquilo que Pêcheux (1997) descreveu como:

(...) uma divisão discursiva entre dois espaços: o da manipulação de significações estabilizadas, normatizadas por uma higiene pedagógica do pensamento e o de transformações de sentido, escapando a qualquer norma estabelecida a priori, de um trabalho de sentido sobre o sentido, tomados no relançar infinito das interpretações (p. 51).

A autora interpreta as colocações do autor afirmando que o sujeito ocupa a posição de autor quando retroage sobre o processo de produção de sentidos, procurando "amarrar" a dispersão que está sempre virtualmente se instalando, devido à equivocidade da língua.

O conceito de autoria proposto por Tfouni (2001, 2006) fortalece sua concepção de letramento e abre possibilidades e caminhos para investigar-se os níveis de letramento, implícitos no "continuum".

É possível também, com base nesses postulados, dizer que não é pelo fato de os textos serem orais ou escritos que se estabelecerá o grau de letramento do sujeito que os produziu.

O conceito de autoria pode, portanto, ser usado para fundamentar o processo de letramento e sua

\footnotetext{
${ }^{2}$ Tfouni (2001) afirma que nas sociedades letradas não existe o iletramento, que equivaleria à ausência total de conhecimento sobre as práticas escritas, e propõe a noção de graus de letramento para descrever os diferentes níveis nos quais se encontram os sujeitos nessas sociedades.
} 
Tfouni, L.V., Pereira, A.C.,Assolini, F.E.P., Sarti, M. \& Adorni A.(2008). O caráter terapêutico da escrita 105

relação com o continuum. E será também o foco deste artigo.

\section{Método}

Utilizou-se o método indiciário, proposto pela Análise do Discurso de filiação francesa (Pêcheux, 1988, 1997), que preconiza a não-transparência dos dados, ou seja: é preciso interpretar indícios lingüístico-discursivos para se atingir a formação discursiva que aloca o sujeito do discurso em uma determinada posição diante da ideologia.

O trabalho de intervenção com esses adultos teve a duração de três meses, com três encontros semanais de uma hora e meia cada.

\section{Participantes}

Participaram do estudo 18 adultos internos em um hospital psiquiátrico de Ribeirão Preto, além de três alfabetizadores, todos com curso superior completo, sendo um aluno de doutorado, outro aluno do mestrado do Programa de Pós-graduação em Psicologia da FFCLRP-USP, e o terceiro formado em Letras.

\section{Material}

Foi utilizado, como material de coleta de dados, um diário de anotações, além de um caderno para cada alfabetizando, lápis, borracha, papel sulfite, pincel atômico, papel pardo e revistas diversas.

\section{Procedimentos de coleta de dados}

Em primeiro lugar, vale ressaltar que os procedimentos que serão descritos a seguir serviam, não como tarefas objetivas a serem cumpridas pelos participantes, mas sim como ponto de partida organizador do trabalho que seria realizado em cada encontro. A cada dia um leque enorme de conteúdos era trazido pelos participantes do grupo, e servia como substrato principal em cima do qual os alfabetizadores trabalhavam as atividades de leitura e escrita.

Utilizou-se, como "gatilho" para o processo, de um alfabeto elaborado em cartolina e fixado na parede da sala de aula - espécie de metáfora da introdução do mundo letrado no ambiente onde o trabalho se desenvolveria. Ao mesmo tempo, este recurso serviu para indiciar o caráter econômico da escrita, visto que, a partir de um conjunto finito e relativamente pequeno de grafemas, pode-se produzir toda e qualquer escrita, numa infinitude de enunciados.

Em seguida, foram introduzidos para os alunos jogos de fichas contendo as letras do alfabeto, que serviriam de apoio concreto para suas escritas iniciais. A primeira atividade proposta remetia à escrita do próprio nome, com o auxílio dessas fichas.

Depois que todos tinham escrito seus nomes em tiras de papel sulfite, elas foram coladas na parede, e para cada um deles foi pedido que procurasse o seu nome e o personalizasse com a colagem de uma figura, ou fazendo um desenho.

Num segundo momento, foi proposta a elaboração de crachás, para que cada participante pudesse se identificar com o próprio nome, e com os dos colegas. A cada encontro, todo participante procurava identificar o seu crachá, e, deste modo, realizavam uma atividade de leitura dos nomes dos outros. Essa prática tornou-se um ritual de início nos encontros, uma vez que todos os participantes, inclusive os alfabetizadores, assim que chegavam à sala procuravam o seu crachá. Ainda com essa referência, foi proposta aos participantes uma atividade de grupo, onde todos circulavam pela sala e, através do nome no crachá, iam identificando os colegas com os quais compartilhavam aquelas atividades de leitura e escrita; aquelas práticas letradas.

Até então, o trabalho era realizado com o uso de folhas de sulfite, as fichas e lápis. O passo seguinte consistiu na distribuição de cadernos a cada participante, que o personalizava escrevendo seu nome na capa. A inauguração da primeira página do caderno deu-se com a proposta de uma atividade que consistia em preencher lacunas em um texto que falava da vida particular de cada um: 1) Meu nome é...; 2) Nasci em ...; 3) Eu sou (profissão) ... .

Seguiu-se outra atividade, estreitamente conectada com essa: foi proposta a escrita do nome do pai e da mãe de cada participante.

Quando o uso do caderno já estava familiar entre os participantes, propôs-se, pela primeira vez, o trabalho de escrever um texto em grupo. Os alfabetizadores serviriam apenas como centro de organização do texto, transpondo para o código escrito 
aquilo que era construído oralmente pelos participantes do grupo. Tanto o tema, como as frases que constituiriam o texto deviam ser trazidas por eles. $\mathrm{O}$ texto foi sendo construído aos poucos e conciliando os conteúdos que cada um trazia.

\section{Resultados}

Durante a escrita do nome de cada um, notouse que o morador S. queria escrever seu nome completo. Apresentava bastante dificuldade, por não conhecer as letras, mas era nítida sua vontade de aprender a escrever o próprio nome, o que o estimulava a primeiro trabalhar com as fichas e depois tentar escrever com o lápis. A primeira vez que escreveu seu nome completo, sorriu e disse à alfabetizadora que o acompanhava nessa atividade: "Senhora Milena, é a primeira vez que eu escrevo o meu nome desde a infância.", e ficou parado olhando o nome escrito na folha sulfite. Tal fato nos remete à noção de que a palavra escrita, em sua materialidade lingüística, pode agir no resgate da subjetividade. S. olhou para o seu nome escrito e se identificou, como se olhasse para a representação de si próprio como um sujeito social e jurídico: um sujeito que tem um nome reconhecido pelos outros e comprometido ao Outro. A esse respeito, Lacan (1998) afirma que a linguagem, com sua estrutura, préexiste à entrada no simbólico: "Também o sujeito, se pode parecer servo da linguagem, o é ainda mais de um discurso em cujo movimento universal seu lugar já está inscrito em seu nascimento, nem que seja sob a forma de seu nome próprio" (Lacan, 1998, p. 498).

Com relação à atividade de preenchimento de lacunas onde os internos deveriam escrever seu nome, o local de nascimento e a profissão, pôde-se perceber que esses enunciados desencadearam a construção de proto-narrativas autobiográficas (Perroni, 1979) $)^{3}$. Atente-se para o fato de que o verbo na frase 3 ("minha profissão é ..."), que identificava a profissão de cada um, está deliberadamente no tempo presente, com a intenção de marcar uma identidade profissional que talvez já estivesse apagada devido à longa permanência em internação, e à medicação. Ao mesmo tempo, com esta atividade, procurou-se substituir, no eixo paradigmático, o rótulo de "louco", "doente mental" ou "asilado", por um outro, que resgatasse a singularidade dos sujeitos, no caso, pedaços de sua identidade, na forma do nome, lugar de nascimento e profissão.

Alguns, com maior dificuldade, primeiro "escreviam" utilizando as fichas, para posteriormente escrever no caderno. Estas escritas, assim como todas as outras produzidas durante as atividades, eram fixadas na parede e, em todo início de encontro, eram lidas, numa atividade ao mesmo tempo de leitura e de retomada da história das escritas de cada um no processo.

Deste modo, a cada encontro, diversos conteúdos emergiam e cada participante trabalhava com sua própria história, independente do que era proposto inicialmente como atividade, o que mostra que propor atividades neste processo é bem diferente da imposição de tarefas que caracteriza o contexto pedagógico da escola tradicional. Cada participante tinha um envolvimento particular com a tarefa, e fazia um uso singular da escrita, o que acarretava uma abertura constante à memória discursiva de cada um, memória esta onde os significantes adquiriam um caráter peculiar e único.

O texto em grupo, mencionado na descrição dos procedimentos de coleta de dados, foi o momento culminante do processo, pois, além de já trazer como base uma estrutura narrativa plena, coroava todo o trabalho de escrita atrelado ao conceito de letramento do qual se falou no início deste artigo.

Eis o texto coletivo construído pela orquestração de várias vozes heterogêneas, numa profusão de frases pronunciadas pelos moradores, as quais foram organizadas pelos alfabetizadores no eixo sintagmático:

\section{Texto - A FAZENDA}

"A Fazenda é um lugar bom de morar. Nela, nós trabalhamos com a terra. Lá tem muita criação: porco, gado, galinha. Lá tinha muito peixe. Nós tomávamos muito café, leite e água de coco. Existe uma dificuldade quando você fica doente porque é longe. Mas, quem tem a sua fazenda que se vire por lá".

\footnotetext{
${ }^{3}$ Proto-narrativas são narrativas embrionárias, que não se constituem ainda como narrativas plenas, mas já incluem alguns elementos destas, como personagens, lugar, algum tipo de ação, etc.
} 
Atente-se ao final do texto para o que se considerou como um gesto de autoria (Tfouni, 2005). A inserção de "Existe uma dificuldade quando você fica doente porque é longe" muda o rumo da significação, pois o objeto do discurso, que antes era fazenda, passa a ser doença. Acompanhando esse movimento de deslizamento metafórico, pode-se ver que o tempo dos verbos percorre três momentos distintos: começa no presente, passa para o passado imperfeito, e volta a ser usado no presente no final do texto. Essas alternâncias no discurso indiciam uma tomada gradativa de consciência da realidade presente.

Sabe-se que o tempo verbal privilegiado pela narrativa em geral é o passado. É o que afirmam, por exemplo, Labov e Waletzky (1967), que, ao salientarem aspectos formais e estruturais das narrativas, referem-se a ela como uma seqüência de eventos recapitulados, com o verbo no passado. No entanto, o início deste texto está no presente, como se os fatos relatados ainda estivessem acontecendo para o sujeito-narrador. Conforme a associação livre se desenrola, no entanto, o passado vem substituir o presente. Em seguida, quase como se fosse uma aceitação, seguem-se os enunciados: "Existe uma dificuldade quando você fica doente, porque é longe. Mas, quem tem a sua fazenda que se vire por lá”. Nota-se aí o efeito terapêutico da escrita, que se manifesta por um desligamento do passado e uma reparação, no presente (através do discurso e da organização da escrita), das memórias e recordações que causam sofrimento. Percebe-se aí como o discurso da escrita (aquele que é organizado com começo, meio e finalização) propicia a emergência da subjetividade, e também possibilita que pequenos gestos de autoria possam ser concretizados, como a produção desse texto, que é coletivo, mas que diz respeito a cada um.

Tfouni (2005) entende o lugar de autoria como aquele em que o sujeito aceita e detém a deriva (possibilidade de os enunciados tornarem-se outros) e controla a dispersão, relançando esses enunciados na cadeia significante, através de movimentos de retroação ao "já dito", que desnaturalizam o efeito de transparência da linguagem por meio de diversas manobras discursivas.
Conforme a mesma definição, a inserção de "Existe uma dificuldade quando você fica doente porque é longe" quebra a expectativa do rumo da significação através da introdução de um outro objeto discursivo: como já foi dito acima, onde se falava de fazenda, passa-se a falar de doença. Esse movimento de substituição permite que se levante um questionamento acerca da transparência da linguagem, e de uma certa naturalização de sentidos, que ocorre porque até então havia uma referência ao significante "fazenda" como um espaço coletivo que se encontrava marcado por significantes estereotipados desta região do sentido, como "café", "porco", "gado".

A inserção do trecho destacado aponta que o significado de "fazenda", já firmado no código da língua, através do efeito de evidência ideológico, é subvertido pelo fluxo de significação que se materializa em "quem tem a sua (...) que se vire por lá". Essa subversão é assegurada porque o sentido de fazenda, naturalizado pelos sentidos já dados socialmente, é subvertido por um significado que ganha eco na maneira particular, por exemplo, pela qual esses moradores lidam com as dificuldades mais gerais de sua condição de saúde mental, e, ao mesmo tempo, com as dificuldades em utilizar a escrita naquele momento. Esse recorte mostra ainda que, para ser possível falar de conflitos, traumas e experiências desagradáveis, é necessário muitas vezes que o sujeito se desloque para uma outra posição discursiva. Tfouni e Carreira (1996) comentam, a esse respeito, que a narrativa torna possível que o sujeito fale de si de maneira disfarçada. O que ocorre neste pequeno texto é que, para falar do aqui e agora, das condições adversas da internação, o sujeito desloca o tempo do verbo para o passado, e coloca o cenário em outro lugar - na fazenda.

Note-se que o afunilamento deste fluxo da significação - que é operado no momento em que o significante "doença" é introduzido - produz-se à revelia dos sujeitos, visto que na cadeia manifesta eles pretendem falar das dificuldades de quem mora em uma fazenda distante em caso de doença. No entanto, eles estão ao mesmo tempo falando sobre sua própria doença e sobre o confinamento no hospital, "longe" de tudo. Estão falando da "dificuldade" que é viver confinado, quando já se teve a experiência de viver livre e solto no espaço de uma fazenda. 
Nesse movimento da significação, no qual os tempos verbais se alternam juntamente com os objetos discursivos, nota-se que, à medida que as associações são feitas, produzindo (escrevendo) coletivamente o texto, o estereótipo sobre fazenda vai sendo substituído por uma visão subjetiva.

O gesto de autoria está em, ao mesmo tempo conter a deriva dos sentidos e subverter o significado já naturalizado do significante "fazenda", remetendoo a outra dimensão do sentido, ou seja, o de uma abertura dos sentidos possíveis de se ligarem a esse significante. Assim, a circulação desses significantes passa a configurar um processo de ressignificação, no qual os sentidos são retomados e relançados de maneira inconsciente, numa abertura controlada à deriva incessante (Pêcheux, 1997). Seguindo Pêcheux (1988), pode-se propor que o processo acima descrito é efeito do trabalho da ideologia, numa maneira de naturalizar os sentidos através da tentativa de apagar a memória sócio-histórica do dizer e a possibilidade de os enunciados tornarem-se outros, processo esse que ocorre, no caso analisado, através de um movimento de retroação do discurso, que ruma para a singularidade da significação.

São estes formatos que abrem o sentido de "fazenda" para as dificuldades mais diversas que esses moradores já encontraram na sua trajetória, inclusive as dificuldades que encontram no dia-a-dia do hospital, as quais se cruzam, não por acaso, naquele momento em que trabalham com a escrita.

Como se vê, o sentido se abre, ao mesmo tempo em que se afunila e se fecha mais uma vez, porque as dificuldades com a escrita, que aparentemente são dificuldades com a parte gráfica da escrita, tiram do recalque os percalços e os enfrentamentos de cada um ao reescrever a própria história, a partir de um outro lugar, que é o lugar de autoria.

\section{Discussão}

Il n'est personne qui ne soit personnellement concerné par la verité (Lacan, 1966, p. 405) ${ }^{4}$.

Dentro desta discussão, pode-se estabelecer aliança com a epígrafe acima. Com Lacan (1998),

\footnotetext{
${ }^{4}$ Tradução nossa: Não há ninguém que não seja pessoalmente concernido pela verdade.
}

foi possível refletir sobre a relação entre sujeito e verdade, ressaltando a impossibilidade de o sujeito escapar da maneira pela qual a verdade o concerne. No caso deste trabalho, os moradores ocupavam a posição discursiva atravessada pelo discurso acerca da loucura e do asilamento. Essa maneira de o psicanalista francês entender as agruras do verbo "ser" aponta para o que pode ser feito, respeitando as condições de uma situação, e também para o que é possível ser feito, a partir das possibilidades.

Não se é o que se diz, ou o que se pretende, ensina dessa maneira Lacan (1998), mas sim o que é mostrado em atos. Estes, após causarem algum tipo de vertigem, impõem-se pela significação que os atravessa e da qual se faz uso.

Neste momento, ponderando sobre os caminhos percorridos por este trabalho, é importante apontar que as produções de linguagem desses moradores deram sinais marcados simbolicamente pelo ressurgimento de suas verdades num espaço institucionalizado em que essas verdades, muitas vezes, são rotineiramente abafadas.

$\mathrm{O}$ processo de alfabetização neste trabalho serviu menos a favor de um ensino formal de habilidades de ler e escrever do que ao enfoque dos aspectos discursivos e terapêuticos da escrita.

A abordagem nele empregada privilegiou a escrita como um produto cultural, o que implicou trilhar um objetivo que transcendeu os padrões da alfabetização na escola: em detrimento da codificação e decodificação de sinais gráficos, o relevante foi construir um espaço onde os moradores pudessem, ao longo do processo de reconstrução da subjetividade através das práticas de leitura e escrita, ocupar uma posição discursiva que se diferenciasse da ocupada por eles, enquanto pacientes, dentro de uma instituição psiquiátrica.

Mas o que isto tem a ver com os resultados conseguidos com o trabalho desenvolvido? Encarase, a partir de agora, essa relação, por diversas perspectivas. Essas atividades foram desenvolvidas junto aos moradores, considerando-se o que era possível fazer diante da situação peculiar em que se encontravam.

Partiu-se desse comprometimento, pautado nas possibilidades encontradas, instituiu-se outro espaço 
para o verbo escutar; em sua dupla voz: ativa e passiva. Esta escuta, que trilhava o caminho de dar voz às dificuldades dos moradores permitiu que esses sujeitos se sentissem autorizados a escutar sua própria voz. Essas possibilidades estão marcadas inicialmente pela iniciativa em se abrir o espaço institucional para a escuta (e assim o desenvolvimento) deste trabalho.

Em seguida, já em contato semanal com os moradores, tais possibilidades alcançaram aquilo que da produção de linguagem foi possível escutar, enquanto se lidava com esse propósito de abrir-lhes um espaço e um lugar subjetivo para trabalharem com a própria escrita.

No espaço hospitalar, em que foi dado espaço para a escrita, há, relembrando Foucault (1980), um sutil mecanismo de controle e de silenciamento do corpo, procurando criar uma docilidade regrada pela obediência sem discussão, através de um olhar que é direcionado para a tentativa de institucionalização da "loucura".

No entanto, esse isolamento imposto através de uma escrita asséptica e racional, retorna, como descreve de Certeau:

[essa voz que é calada] volta a aparecer fora dessa escritura transformada em meio e em efeito da produção. Ela renasce ao lado, vindo de um além das fronteiras atingidas pela expansão da empresa escriturística. Uma outra coisa ainda fala, e ela se apresenta aos senhores sob as figuras diversas do nãotrabalho: o selvagem, o louco, a criança, até mesmo a mulher, depois, recapitulando muitas vezes as precedentes, sob a forma de uma voz ou dos gritos do Povo excluído da escrita (...) (Certeau, 1994, p. 252).

Contrariamente à assepsia imposta pelas leis escriturais dominantes, instalou-se a polifonia, que rompe o silenciamento ao qual está exposta esta população asilada, polifonia essa que abre a possibilidade para ser atingida a unidade imaginária do corpo (perdida para esses moradores em virtude da patologia), em função do resgate de fatos memoráveis comprometidos com a singularidade das experiências de vida de cada um.

Com este debate, sinaliza-se, por exemplo, que não foi dada tanta importância, dentro dos limites do trabalho, em buscar detalhes nos protocolos dos moradores acerca da veracidade dos acontecimentos que relatavam, mas antes em apontar-lhes a importância do encadeamento da escrita em seu formato de unidade (começo, meio e fim), do ponto de vista do imaginário e da autoria.

Marcou-se, deste modo, o caráter de interação social da escrita, a necessidade em apontar para os moradores a existência de um código, ao qual se está submetido, e que é preciso respeitar, que é o código da língua?

\section{Referências}

Certeau, M. (1994). A invenção do cotidiano: A arte de fazer (pp. 247-258). Petrópolis, RJ: Vozes.

Foucault, M. (1969). O que é o autor? Lisboa, Portugal: Passagens.

Foucault, M. (1980). O nascimento da clínica (2a ed.). Rio de Janeiro: Forense Universitária.

Gallo, S. L. (1995). Discurso da escrita e ensino. Campinas, SP: EdUNICAMP.

Heath, S. B. (1986). Critical factors in literacy development. In S. Castell, A. Lucke \& K. Egan. Literacy, society and schooling: A reader (pp. 159-175). New York: Cambridge University Press.

Kleiman, A. B. (1995). Os significados do letramento: Uma nova perspectiva sobre a prática social da escrita. Campinas, SP: Mercado de Letras.

Labov, W., \& Waletzky, J. (1967). Narrative analysis: Oral versions of personal experience. In J. Helm (Ed.), Essays on the verbal and visual arts (pp. 12-44). Seattle, WA: University of Washington Press.

Lacan, J. (1966). La chose freudienne ou sens du retour à Freud en Psychanalyse (pp. 401-436). In J. Lacan, Écrits. Paris: Seuil.

Lacan, J. (1998). Escritos. Rio de Janeiro: Zahar.

Maingueneau, D. (1989). Novas tendências em análise do discurso. Campinas, SP: EdUNICAMP.

Olson, D. R. (1986). Learning to mean what you say: Toward a psychology of literacy. In S. Castell, A. Lucke \& K. Egan. Literacy, society and schooling: A reader (pp. 145-158). New York: Cambridge University Press. 
Orlandi. E. P., \& Guimarães, E. (1988). Unidade e dispersão: Uma questão do texto e do sujeito (Cadernos PUC, Vol. 1). São Paulo: EPUC.

Pêcheux, M. (1988). Semântica e discurso: Uma crítica à afirmação do óbvio. Campinas, SP: EdUNICAMP.

Pêcheux, M. (1997). O discurso: Estrutura ou acontecimento. Campinas, SP: Pontes.

Perroni, M. C. (1979). Ensaiando narrativas: Do jogo de contar às proto-narrativas (Série Estudos, Vol. 6). Uberaba, MG: FISTA.

Tfouni, L. V. (1992a). O dado como indício e a contextualização: Do(a) pesquisador nos estudos sobre compreensão da linguagem. D.E.L.T.A., $8(2), 205-223$.

Tfouni, L. V. (1992b). Letramento e analfabetismo. Tese de livre-docência não publicada, Universidade de São Paulo, Ribeirão Preto.

Tfouni, L. V. (1994). Perspectivas históricas e ahistóricas do letramento. Cadernos de Estudos Lingüísticos, 26, 49-62.

Tfouni, L. V. (2001). A dispersão e a deriva na constituição da autoria e suas implicações para uma teoria do letramento. In I. Signorini (Org.), Investigando a relação oral/escrito e as teorias do letramento (pp. 77-97). Campinas, SP: Mercado de Letras.

Tfouni, L. V. (2005). Letramento e autoria: Uma proposta para contornar a dicotomia oral e escrita. Revista da ANPOLL, 18, 127-141.

Tfouni, L.V. (2006). Letramento e alfabetização (8a ed.). São Paulo: Cortez, 2006.

Tfouni, L. V., \& Carreira, A. F. (1996). Narrativas de crianças de rua brasileiras: Uma forma de falar de si mesmo". Cadernos de Pesquisa NEP, 2(2), 1-12.

Tfouni, L. V., \& Seidinger, F. M. (1997). Literacy practices in a mental health hospital: A bridge to recover lost subjectivity. International Journal of Psycholinguistics, 3(38), 297-310.
Artigo recebido em 01/08/2006.

Aceito para publicação em 09/06/2007.

Endereço para correspondência:

Leda Verdiani Tfouni. Rua Maria Octavia P. Villa, 71. CEP 14021-047. Ribeirão Preto-SP, Brasil. E-mail: lvtfouni@usp.br

Agradecimentos

Às agências de fomento CAPES, FAPESP, CNPq e aos profissionais do Hospital Santa Tereza de Ribeirão Preto-SP.

Leda Verdiani Tfouni é Professor Titular da Faculdade de Filosofia, Ciências e Letras de Ribeirão Preto da Universidade de São Paulo.

Anderson de Carvalho Pereira é mestre e doutorando pelo Programa de Pós-graduação em Psicologia da Faculdade de Filosofia, Ciências e Letras de Ribeirão Preto da Universidade de São Paulo, bolsista FAPESP.

Filomena Elaine de Paiva Assolini é Professor Doutor da Faculdade de Filosofia, Ciências e Letras de Ribeirão Preto da Universidade de São Paulo.

Milena Sarti é mestre e doutoranda pelo Programa de Pós-graduação em Psicologia da Faculdade de Filosofia Ciências e Letras de Ribeirão Preto da Universidade de São Paulo, bolsista CAPES.

Alessandra Adorni é mestranda pelo Programa de Pós-graduação em Psicologia da Faculdade de Filosofia Ciências e Letras de Ribeirão Preto da Universidade de São Paulo. 